\title{
ABILITY TO PAY AND WILLINGNESS TO PAY FOR COVID-19 VACCINATION: ARE WE READY?
}

\author{
Amirah Azzeri ${ }^{1}$, Nur Amalina Abd Laziz ${ }^{1}$, Muslimah Ithnin ${ }^{1}$ and Hafiz Jaafar ${ }^{1 *}$ \\ ${ }^{1}$ Public Health Unit, Department of Primary Health Care, Faculty of Medicine and Health Sciences, \\ Universiti Sains Islam Malaysia
}

Corresponding author: Mohd Hafiz Bin Jaafar

Email: dr.hafizjaafar@usim.edu.my

\begin{abstract}
Vaccinations were considered to be among the most effective way in preventing further COVID-19 transmission. To date, the manufactures of vaccines were in the third phase of clinical trial studies. However, the extent to which the publics are able to pay and willing to pay for this vaccine remains unclear. This study aimed to evaluate the ability to pay (ATP) and willingness to pay (WTP) for COVID-19 vaccination in Malaysia. A cross sectional study was conducted among 67 staff of a public university in Nilai, Negeri Sembilan. The ATP and WTP were obtained through an open and close-ended method via either face-to-face interview or telephone-based interview. For the open-ended method, the mean (SD) ATP and WTP values recorded were USD 52.35 (620.83) and USD 52.08 (620.82) respectively. As for the closeended, the mean (SD) ATP and WTP values recorded were USD 52.08 (620.82) and USD 32.38 (147.97) respectively. Through closed-ended method, lower ATP and WTP values were recorded compared with open-ended method, as the respondents are able to negotiate through a bidding process to get the best price of vaccine. Female, Malay, married, permanent staff and respondents with side-income respondents recorded higher ATP and WTP values in open-ended method. Nevertheless, except for the side-income, other factors in this study were not statistically significant. Findings from this study could facilitate government to set appropriate market price to ensure the affordability of COVID-19 vaccine and improve its accessibility so that a big proportion of the people will be vaccinated and protected from this disease.
\end{abstract}

Keywords: Ability to pay (ATP), Willingness to pay (WTP), Vaccine, Financial COVID-19.

\section{INTRODUCTION}

Coronavirus disease 2019 (COVID-19) is caused by a new coronavirus first identified as a novel severe acute respiratory syndrome coronavirus 2 (SARS-CoV-2). The first case was reported on December 31, 2019 in Wuhan City, China ${ }^{1}$. Since then, the new coronavirus has spread and infected people in more than 200 countries. Due to the rapid spread of the disease, the World Health Organization (WHO) declared the COVID-19 as pandemic on Mac $2020^{2-4}$.

The positive cases of pandemic COVID-19 were continuously increasing and in early February 2021, the confirmed cases were around 106 million with approximately 2 million death were recorded globally ${ }^{2}$. In Malaysia, the updated total positive cases as in 7 February 2021 was 238,721 with 857 deaths $^{5}$. SARS-CoV-2 spreads rapidly from person to person ${ }^{6}$ through direct transmission via respiratory droplet or direct contact with infected individuals, or through contact with contaminated objects and surfaces $^{7,8}$. The symptoms of COVID-19 are anosmia, dry cough, headache, sore throat, vomiting, fever, diarrhea and nasal congestion?. There are some infected individuals who do not develop any symptoms and do not feel unwell. These people are called asymptomatic carriers ${ }^{10}$.
Nevertheless, certain groups of people such as the elderly, young children, pregnant ladies, and people with chronic diseases such as hypertension, diabetes, heart problems, kidney and liver diseases are highly vulnerable and susceptible to COVID-19 infection and complications ${ }^{6,11}$.

To date, there is no specific treatment confirmed by the WHO to be effective against COVID-1912. Therefore, lots of nonpharmacological preventive measures were taken to break the transmission chain. In Malaysia, the Movement Control Order (MCO) was enforced under the Prevention and Control of Infectious Disease Act 1988 and the Police Act $1967^{7}$. During the MCO phase, all mass movements, sports, socio-cultural or religious activities were prohibited. Schools, universities and non-essential public and private were also closed. Travel banned, borders restrictions and compulsory quarantine for those coming back from overseas were also implemented ${ }^{13}$. An individual self-precaution was emphasized to avoid exposure through staying at home, practiced wearing protective masks when out in public, frequent hand-washing, and avoiding mass gathering ${ }^{7,14-16}$. 
COVID-19 pandemic had given huge consequences and impairment towards human's physical, emotional, and psychosocial wellbeing ${ }^{17-19}$, thus enhanced the need for an effective vaccine as it is among the most efficient means of preventing further COVID-19 transmission ${ }^{20}$. Vaccines provide direct protection by reducing susceptibility to infection or diseases and indirect protection by reducing the number of people infected in a population or their infectiousness ${ }^{21}$. It works by training and preparing the body's natural defenses which is the immune system to recognize and fight off the viruses and bacteria. If the body is exposed to those pathogens later, the body is immediately ready to destroy them ${ }^{2}$.

The development of a vaccine against COVID-19 were done by various institutions funded from multiple governments, pharmaceutical companies and philanthropists ${ }^{20,22-25}$. Around the world, more than 50 vaccines for the COVID-19 are being tested in three phases of clinical trials with at least 80 others in earlier stage of development ${ }^{2}$. Even though the vaccine were deemed to be very effective in preventing further infections of the pandemic, the ability-to-pay (ATP) and willingness-to-pay (WTP) for the vaccine were still not clear. There might be individuals who were not willing to pay for the vaccine because they were not convinced of its effectiveness and importance. Some of them might not be able to pay for the vaccine due to the existing commitments. The ATP and WTP for the vaccine were usually associated with the factors that determined them to set the value ${ }^{26-28}$.

Hence, it is crucial to determine the individual's ATP and WTP for the vaccine. Assessment of WTP, known as the maximum amount of money that individuals would be willing to pay for a vaccine, not only determine the potential market but also give information that could be incorporated in formulating the best payment strategy for a new COVID-19 vaccine ${ }^{29}$. The WTP also highlights the current context on the level of 'out of pocket' payments a person is ready to accept to avoid health losses or reduce health risks for themselves and their community ${ }^{30}$. Therefore, this study aimed to identify the participant's ATP and WTP for COVID-19 vaccination in Malaysia.

\section{METHODS}

\section{Study background}

A cross-sectional study was conducted among staff of a public university in Nilai, Negeri Sembilan from July to December 2020. Various group of staff such as academician, administrative and supporting staff were included in the study. The study participants were recruited through a convenience sampling based on the list name given by the Head of Departments/Directors/Deans. The study participants were contacted and consents were taken prior to data collection.

\section{Study tools}

A validated questionnaire was used for data collection on the socio-demographic characteristics, ATP and WTP for COVID-19 vaccination based on previous study ${ }^{31}$. This questionnaire was divided into two sections, Section A and B. Section A consists of questions constructed to obtain the baseline information of the study participants while Section B was designed to collect information on the ATP and WTP for COVID-19 vaccination.

\section{Data collection}

Hybrid method was applied for data collection process. Information on the socio-demographic characteristics were collected through online medium using a Google form. As for the ATP and WTP data, it was collected through either faceto-face interview or telephone-based interview. Open and close-ended method was used to collect the value for ATP and WTP29,30. For open-ended method, the study participants were asked about the amount they are willing to pay and able to pay for COVID-19 vaccination. This amount was expressed in Ringgit Malaysia (was converted to US Dollar later), which represents how much of COVID-19 vaccine a person was able and willing to pay. is autonomy to state their maximum ATP and WTP. Following the open-ended question, the researchers suggested different prices step by step in a bidding fashion with the respondents. is depending on the answers given. ilepiThe prices were increased or decreased each time the respondent accepted or said 'yes' to the initial bid, and each time the respondent rejected or said ' $n o$ ' to the initial bid respectively. 'L 'Ibidding continued until the respondent accepted the bid and the accepted bid would be the estimated ATP and WTP for that particular respondent. This method gave more accurate and reliable prices on top of the findings from openended question.

\section{Data analysis}

Descriptive analysis was conducted to determine the socio-demographic characteristics of the study population and the value of ATP and WTP. Results for continuous data were presented as mean and standard deviation (median and interquartile range for skewed data). For categorical data, the results were presented as frequency and percentage. Bivariate analysis was done to establish any relationship between the exposure variables (socio-demographic characteristics) with the outcome variables (ATP and WTP). For bivariate analysis, level of significance was pre-set at 0.05. Mann-Whitney, Kruskal-Wallis and Spearman Correlation test were conducted to determine the association between all the exposure and outcome variables 
(depending on the type of exposure variables). All the data were analyzed using SPSS Software version 22 .

This study was approved by the Ethics Committee of Universiti Sains Islam Malaysia (USIM). Written informed consent was obtained from the subjects prior to data collection.

\section{RESULTS}

\section{Descriptive Analysis}

The total number of populations included in this study was 67 . The mean (SD) age for the study population was $37.9(8.12)$. Almost all of them were Malay $(n=66,98.5 \%)$ with almost equal distribution between male $(n=30,44.8 \%)$ and female $(n=37,55.2 \%)$. Majority were married ( $n$
$=55,82.1 \%)$, received tertiary education $(n=55$, 82.1\%) and work as a permanent staff ( $n=47$, $70.1 \%)$. About $9(13.4 \%)$ had side income and 19 (28.4\%) received financial aid support. Only 15 $(22.4 \%)$ of them reported that they had at least one chronic illness such as diabetes mellitus, hypertension or hypercholesterolemia. The mean (SD) monthly household income reported was USD 1439.6. Results for socio-demographic characteristics were summarized in Table 1.

For the open-ended method in Section B, the mean (SD) ATP and WTP values recorded were USD 52.35 (620.83) and USD 52.08 (620.82) respectively. As for the close-ended, the mean (SD) ATP and WTP values recorded were USD 52.08 (620.82) and USD 32.38 (147.97) respectively (Table 2).

Table 1: Socio-demographic characteristics

\begin{tabular}{llcc}
\hline Variables & & Frequency & Percentage \\
\hline Gender & Male & 30 & 44.8 \\
Ethnicity & Female & 37 & 55.2 \\
& Malay & 66 & 98.5 \\
Marital Status & Others & 1 & 1.5 \\
Education & Single & 12 & 17.9 \\
& Married & 55 & 82.1 \\
Working Status & Secondary & 12 & 17.9 \\
& Tertiary & 55 & 82.1 \\
Side Income & Permanent & 47 & 70.1 \\
\multirow{3}{*}{ Financial Aid } & Temporary & 20 & 29.9 \\
& Yes & 9 & 13.4 \\
Chronic Illness & No & 43 & 64.2 \\
& Yes & 19 & 28.4 \\
& No & 48 & 71.6 \\
& Yes & 15 & 22.4 \\
& No & 52 & 77.6 \\
\hline
\end{tabular}

Table 2: Association between socio-demographic characteristics with ATP and WTP

\begin{tabular}{llc}
\hline & Mean & SD \\
\hline Age & 37.9 & 8.12 \\
Household Income* $^{*}$ & 1439.6 & 3421.89 \\
ATP (Open-ended)* & 52.35 & 620.83 \\
WTP (Open-ended)* & 52.08 & 620.82 \\
ATP (Close-ended)* & 34.63 & 160.07 \\
WTP (Close-ended)* & 32.38 & 147.97 \\
\hline
\end{tabular}


Normality testing was conducted to determine the distributions of ATP and WTP values. Since the distributions were skewed, Mann-Whitney test was chosen to determine the association between gender, ethnicity, marital status, education level, working status, side-income, financial aid and chronic illness with the ATP and WTP values. For age and monthly household income, Spearman Correlation test was

conducted to determine their correlation with the ATP and WTP values.

Overall, higher ATP and WTP values were recorded using an open-ended compared to closeended method. For open-ended method, higher mean (SD) ATP/WTP values were recorded among those with tertiary education USD 55.42 (668.52)/ USD 55.15 (668.49), no side income USD 33.06 (167.19)/ USD 32.89 (171.48), have financial aid USD 29.80 (216.52)/ USD 32.77 (221.14) and no chronic illness USD 58.50 (701.69)/ USD 58.68 (702.28). This trend was consistent for closeended method, with lower values recorded.

Nevertheless, different trend was observed between open-ended and close-ended method for gender, ethnicity, marital status and working status. For open-ended method, higher mean (SD) ATP/WTP values were recorded for female USD 58.55 (806.58)/ USD 58.63 (807.51), Malay USD 52.84 (625.37)/ USD 52.57 (625.36), married USD 55.27 (680.59)/ USD $54.51 \quad(681.34)$ and permanent staff USD 54.29 (728.34)/ USD 53.92 (728.26). In contrary, the ATP and WTP values were higher among the opposite groups compared to open-ended method. For close-ended method, higher mean (SD) ATP/WTP values were recorded for male USD 40.37 (216.50)/ USD 38.16 (206.51), non-Malay USD 49.02(0.00)/ USD 49.02 (0.00), single USD 48.53 (204.44)/ USD 43.63 (167.12) and temporary staff USD 43.26 (231.41)/ USD 43.01 (223.85).

However, except for the association between side-income with ATP value from open-ended method $(p$-value $=0.008)$, other results were not significance with $\mathrm{p}$-values recorded were all more than 0.05. Spearman correlation test conducted also showed no significant association between age and household income with ATP and WTP from both open-ended and close-ended method. Results for Spearman correlation test and MannWhitney test were summarized in Table 3 and Table 4 respectively.

Table 3: Correlation between age and household income with WTP and ATP

\begin{tabular}{llcccc}
\hline & & ATP Open- & WTP Open- & ATP Close- & WTP Close-ended \\
& & ended & ended & ended & \\
\hline Age & $r$ & 0.017 & 0.001 & -0.104 & -0.054 \\
& p-value & 0.894 & 0.999 & 0.407 & 0.668 \\
Household Income & $\mathrm{r}$ & 0.148 & 0.106 & 0.125 & 0.156 \\
& p-value & 0.231 & 0.395 & 0.313 & 0.206
\end{tabular}

${ }^{*}$ All values were in Ringgit Malaysia

\section{DISCUSSION}

This study reports the ability and willingness of the respondents to pay for the COVID-19 vaccination. To date, from more than 50 COVID19 vaccine candidates in trials, 10 manufacturers of vaccines were currently in the phase 3 of clinical trial studies. Among them were AstraZeneca, Pfizer-BioNTech and Sinovac ${ }^{32}$. In December 2020, the United Kingdom (UK) became the first country in the world that approved the COVID-19 vaccine produced Pfizer-BioNTech to be used in their country. A 90-year-old man became the first patient to receive the vaccine and since then, more than a million of people in the UK were vaccinated $^{32}$.

In Malaysia, the Ministry of Health is currently monitoring the effectiveness and side effects of the 10 vaccines that entered the third phase of clinical trial studies. Agreements were made with AstraZeneca, Pfizer and COVAX to supply the vaccines for the people in Malaysia. Terms Sheet agreements were also made with Pharmaniaga Lifescience Sdn. Bhd. (PLS) and Duopharma (M) Sdn. Bhd to supply Vero Cell vaccine by Sinovac Life Science Co Ltd and Sputnik V by Gamaleya Research Instistute of Epidemiology and Microbiology in Russia. In addition, collaboration was also made with the Institute of Medical Biology China Academy of Medical Sciences (IMBCAMS) to conduct a phase 3 clinical trial in Malaysia. The trial began on January 27, 2021 after approval was given by the National Pharmaceuticals Regulatory Agency (NPRA) on January 8, 20215,33. 
In this study, we found that the mean WTP value recorded was USD 52.08 (620.2). This is higher than a web-based survey conducted in April 2020 among Malaysian, which recorded a mean WTP value of USD 32.87 (79.2). Our finding also recorded a higher mean WTP value compared to the WTP for hypothetical dengue vaccine (USD $9.38)^{20}$. The different could be associated with the increased in knowledge and awareness on the COVID-19 impact and complications. After more than a year in the pandemic era, majority of people resorted for more definite solution thus explained the higher WTP value for COVID-19 vaccine recorded in our study.

Similar WTP value was also reported by a study conducted in Indonesia. The WTP value of USD 56.76 for COVID-19 vaccine was recorded using dichotomous contingent valuation approach. Nevertheless, higher WTP values for COVID-19 vaccine were recorded in Ecuador (USD 146.48), Chile (USD 183.30) and China (USD 294.52). Among the factors that contributed to the differences could be the average percapita income, healthcare system, insurance coverage and premium, severity and impact of COVID-19 infection, government policy and subsidiary received by those people $22,24,29,30$.

In this study, we used both open and close-ended method to measure the ATP and WTP values. This allows us to have extensive and thorough estimation of both values. Higher ATP and WTP values were recorded using an open-ended compared to a close-ended method. In the openended method, respondents got the full autonomy and freedom to state their maximum ATP and WTP values. For the close-ended method, lower ATP and WTP values were reported since we allowed the respondents to negotiate through a bidding process to get the best price. Most of the respondents accepted the lowest price in initial bid and rejected the bidding process as the price increased. Most of the accepted bidding prices in the close-ended method were lower compared to the stated price in the open-ended method. Some of them also asked the possibility of receiving free-of-charge COVID-19 vaccine during the interview.

The ATP and WTP values for the COVID-19 vaccine were influenced by the respondent's monthly household income, financial aid, marital status, gender, age, education level, working status, side-income and chronic illness ${ }^{20,22,29,30}$. Similar to other studies, respondents with tertiary education recorded the highest value of ATP and WTP of vaccines in both open and close ended method. This could be due to the fact that they might had higher awareness level on the needs of vaccine to prevent COVID-19 infection ${ }^{20,29}$. Higher
ATP and WTP values were also recorded among female, Malay, married and permanent staff respondents in an open-ended method. Female gave more value to pay for the COVID-19 vaccine, as they are more health conscious and have higher health literacy level compared to male ${ }^{34}$. Married and permanent staffs were believed to have higher household income. Hence, they were able to allocate some amount of money to pay for the vaccine compared to the single respondents and temporary staffs ${ }^{20,22,23,29}$. Similarly, higher ATP and WTP values were also recorded among respondents with side-income. Nevertheless, except for the side-income, other factors in this study were not statistically significant. Since this is only a preliminary study, the findings were expected as the sample size was small and our study population was homogenous. At the moment, we are planning for a larger scale study at the national level to improve our findings and measurement of ATP and WTP values for COVID19 vaccine.

At the moment, COVID-19 vaccines were fully subsidised by the Malaysian government. Nevertheless, should the need arises, the cost of getting vaccinated might need to be incurred through out-of-pocket payment. Therefore, this study could be used as the reference to set an affordable market price to achieve disease control as well as to not burden the population.

\section{CONCLUSION}

As COVID-19 vaccine is currently been used, we need to anticipate its economic impact and consequences. An economic analysis to estimate the potential consequences of this pandemic to our country and forecast different national strategies would help to inform national decisionmaking in relation to the development of national policies for COVID-19 pandemic. Findings from this study could also facilitate government to set appropriate market price to ensure the affordability of COVID-19 vaccine and improve its accessibility so that a big proportion of the people will be vaccinated and protected from this disease.

\section{Conflict of interest}

The authors declare no potential; conflict of interest.

\section{Acknowledgements}

We would like to show our appreciation towards Universiti Sains Islam Malaysia (USIM) for providing fund to conduct this study through COVID Grant USIM (P1-17-15120-UNI-CVD-FPSK) 
Malaysian Journal of Public Health Medicine 2021, Vol. 21 (1): 347-355

Table 4: Association between socio-demographic characteristics with ATP and WTP

\begin{tabular}{|c|c|c|c|c|c|c|c|c|c|}
\hline \multirow[t]{2}{*}{ Variables } & & Mean (SD) ATP & $p$-value & Mean $\quad(S D)$ WTP & p-value & Mean (SD) ATP & p-value & $\begin{array}{lll}\text { Mean } & \text { (SD) } & \text { WTP }\end{array}$ & p-value \\
\hline & & \multicolumn{2}{|l|}{ Open-ended } & \multicolumn{2}{|l|}{ Open-ended } & \multicolumn{2}{|l|}{ Close-ended } & \multicolumn{2}{|l|}{ Close-ended } \\
\hline \multirow[t]{2}{*}{ Gender } & Male & $44.68(260.33)$ & 0.714 & $44.04(256.25)$ & 0.699 & $40.37(216.50)$ & 0.286 & $38.16(206.51)$ & 0.243 \\
\hline & Female & $58.55(806.58)$ & & $58.63(807.51)$ & & $30(91.60)$ & & $27.67(70.35)$ & \\
\hline \multirow[t]{2}{*}{ Ethnicity } & Malay & $52.84(625.37)$ & 0.83 & $52.57(625.36)$ & 0.832 & $34.44(161.13)$ & 0.715 & $32.13(148.86)$ & 0.647 \\
\hline & Non-Malay & $19.61(0.00)$ & & $19.61(0.00)$ & & $49.02(0.00)$ & & $49.02(0.00)$ & \\
\hline \multirow[t]{2}{*}{ Marital Status } & Single & $43.14(201.06)$ & 0.821 & $45.59(187.87)$ & 0.868 & $48.53(204.44)$ & 0.166 & $43.62(167.12)$ & 0.298 \\
\hline & Married & $55.27(680.59)$ & & $54.51(681.34)$ & & $30.27(144.85)$ & & $30.39(146.42)$ & \\
\hline \multirow[t]{2}{*}{ Education } & Secondary & $36.76(283.69)$ & 0.713 & $36.54(283.85)$ & 0.714 & $30.98(132.23)$ & 0.737 & $29.41(40.79$ & 0.769 \\
\hline & Tertiary & $55.42(668.52)$ & & $55.15(668.49)$ & & $35.37(165.87)$ & & $32.97(151.37)$ & \\
\hline \multirow[t]{2}{*}{ Working Status } & Permanent & $54.29(728.34)$ & 0.874 & $53.92(728.26)$ & 0.881 & $30.98(117.79)$ & 0.244 & $27.84(97.72)$ & 0.118 \\
\hline & Temporary & $47.80(232.50)$ & & $47.80(233.07)$ & & $43.26(231.41)$ & & $43.01(223.85)$ & \\
\hline \multirow[t]{2}{*}{ Side-income } & No & $32.95(167.19)$ & 0.008 & $32.90(171.48)$ & 0.07 & $31.64(131.29)$ & 0.409 & $28.65(111.84)$ & 0.231 \\
\hline & Yes & $13.33(31.27)$ & & $14.98(29.35)$ & & $25.88(37.12)$ & & 25.89(39.09) & \\
\hline \multirow[t]{2}{*}{ Financial Aid } & No & $29.56(109.86)$ & 0.983 & $28.09(111.39)$ & 0.679 & $28.60(109.39)$ & 0.516 & $28(96.02)$ & 0.945 \\
\hline & Yes & $29.80(216.52)$ & & $32.77(221.14)$ & & $34.20(139.42)$ & & $28(116.29)$ & \\
\hline \multirow[t]{2}{*}{ Chronic Illness } & No & $58.50(701.69)$ & 0.542 & $58.68(702.28)$ & 0.513 & $36.62(170.72)$ & 0.446 & $34.17(160.35)$ & 0.454 \\
\hline & Yes & $31.05(113.81)$ & & 29.24(91.14) & & 27.77(116.29) & & 26.15(93.09) & \\
\hline
\end{tabular}




\section{REFERENCE}

1. Acuti Martellucci C, Flacco ME, Cappadona R, Bravi F, Mantovani L, Manzoli L. SARS-CoV-2 pandemic: An overview. Adv Biol Regul [Internet]. Elsevier Ltd; 2020 Aug 1 [cited 2020 Nov 28];77. Available from: https://doi.org/10.1016/j.jbior.2020.100 736

2. World Health Organization. WHO announces COVID-19 outbreak. 2020.

3. Jaafar H, Azzeri A. Winning The War Against Covid-19 in Malaysia: An Achievable Goal? Malaysian J Public Heal Med. 2020;20(1):148-9.

4. Azzeri A, Jaafar H, Dahlui M, Othman S, Tunku Kamarul Z. Prediction of diseases burden and healthcare resource utilization through simple predictive analytics using mathematical approaches, an experience from University of Malaya Medical Centre. J Univ Malaya Med Cent. 2020;1(3):10-5.

5. Ministry of Health Malaysia. Current situation of COVID-19 pandemic in Malaysia [Internet]. 2020 [cited 2021 Jan 13]. Available from: http://covid19.moh.gov.my/

6. Elengoe A. COVID-19 outbreak in Malaysia [Internet]. Osong Public Health and Research Perspectives. Korean Disease Control and Prevention Agency; 2020 [cited 2021 Feb 1]. p. 93-100. Available from:

https: / /doi.org/10.24171/j.phrp.2020.11 .3 .08

7. Shah AUM, Safri SNA, Thevadas R, Noordin NK, Rahman AA, Sekawi Z, et al. COVID-19 outbreak in Malaysia: Actions taken by the Malaysian government. Int J Infect Dis [Internet]. Elsevier B.V.; 2020 Aug 1 [cited 2020 Nov 28];97:108-16. Available from:

https://pubmed.ncbi.nlm.nih.gov/32497 808/

8. Albitar O, Ballouze R, Ooi JP, Maisharah S, Ghadzi S. Risk factors for mortality among COVID-19 patients. [cited 2020 Nov 29]; Available from: https://doi.org/10.1016/j.diabres.2020. 108293

9. Huang $C$, Wang $Y$, Li X, Ren L, Zhao J, Hu $Y$, et al. Clinical features of patients infected with 2019 novel coronavirus in Wuhan, China. Lancet [Internet]. Lancet Publishing Group; 2020 Feb 15 [cited 2021
Feb 1];395(10223):497-506. Available from: https: / / isaric.tghn.org/protocols/

10. Manivannan M, Jogalekar MP, Kavitha MS, Maran BAV, Gangadaran P. A mini-review on the effects of COVID-19 on younger individuals [Internet]. Experimental Biology and Medicine. SAGE Publications Inc.; 2020 [cited 2020 Nov 28]. Available from:

https: //pubmed.ncbi.nlm.nih.gov/33210 552/

11. Lim Heng Sim B, Kumar Chidambaram S, $C i$ Wong $X$, Dass Pathmanathan $M$, Peariasamy KM, Peng Hor C, et al. Clinical characteristics and risk factors for severe COVID-19 infections in Malaysia: A nationwide observational study-NC-ND license

http://creativecommons.org/licenses/by -nc-nd/4.0/ ). Lancet Reg Heal Pacific [Internet]. 2020 [cited 2020 Nov 29];4:55. Available from: https://doi.org/10.1016/j.lanwpc.2020.1 0

12. Singhal T. A Review of Coronavirus Disease-2019 (COVID-19) [Internet]. Indian Journal of Pediatrics. Springer; 2020 [cited 2021 Feb 1]. p. 281-6. Available from: https: / /doi.org/10.1007/s12098-02003263-6

13. Ganasegeran K, Ch'ng ASH, Looi I. COVID19 in Malaysia: Crucial measures in critical times. Journal of global health. NLM (Medline); 2020. p. 20333.

14. Alsayed A, Sadir H, Kamil R, Sari H. Prediction of epidemic peak and infected cases for COVID-19 disease in Malaysia. Int J Environ Res Public Health [Internet]. MDPI AG; 2020 Jun 1 [cited 2020 Nov 28];17(11):1-15. Available from: https: / / pubmed.ncbi.nlm.nih.gov/32521 641/

15. Singh S, Sundram BM, Rajendran K, Law $\mathrm{KB}$, Aris $\mathrm{T}$, Ibrahim $\mathrm{H}$, et al. Forecasting daily confirmed COVID-19 cases in Malaysia using ARIMA models. J Infect Dev Ctries [Internet]. Journal of Infection in Developing Countries; 2020 Sep 1 [cited 2020 Nov 28];14(9):971-6. Available from: https: //pubmed.ncbi.nlm.nih.gov/33031 083/

16. Rampal L. COVID-19 pandemic update. Med J Malaysia. 2020;75(3):195.

17. Wong LP, Alias H. Temporal changes in psychobehavioural responses during the early phase of the COVID-19 pandemic in 
Malaysia. J Behav Med [Internet]. Springer; 2020 [cited 2020 Nov 28]; Available from: https://pubmed.ncbi.nlm.nih.gov/32757 088/

18. Kalok A, Sharip S, Hafizz AMA, Zainuddin $Z M$, Shafiee MN. The psychological impact of movement restriction during the COVID-19 outbreak on clinical undergraduates: A cross-sectional study. Int J Environ Res Public Health [Internet]. MDPI AG; 2020 Nov 2 [cited 2020 Nov 28];17(22):1-13. Available from: https://pubmed.ncbi.nlm.nih.gov/33212 969/

19. Azlan AA, Hamzah MR, Sern TJ, Ayub SH, Mohamad E. Public knowledge, attitudes and practices towards COVID-19: A crosssectional study in Malaysia. PLoS One. 2020;15(5):1-15.

20. Wong LP, Alias $\mathrm{H}$, Wong $\mathrm{PF}$, Lee HY, AbuBakar $\mathrm{S}$. The use of the health belief model to assess predictors of intent to receive the COVID-19 vaccine and willingness to pay. Hum Vaccines Immunother [Internet]. Taylor \& Francis; 2020;16(9):2204-14. Available from: https://doi.org/10.1080/21645515.2020. 1790279

21. Halloran ME, Longini IM, Struchiner CJ. Design and analysis of vaccine studies [Internet]. New York, NY: Springer New York; 2010 [cited 2021 Feb 1]. Available from:

http: / / link.springer.com/10.1007/978-0387-68636-3

22. Sarasty O, Carpio CE, Hudson D, GuerreroOchoa PA, Borja I. The demand for a COVID-19 vaccine in Ecuador. Vaccine. 2020. p. $8090-8$.

23. García LY, Cerda AA. Contingent assessment of the COVID-19 vaccine. Vaccine. 2020. p. 5424-9.

24. Dong D, Xu RH, Wong EL yi, Hung CT, Feng $D$, Feng $Z$, et al. Public preference for COVID-19 vaccines in China: A discrete choice experiment. Heal Expect. 2020;23(6):1543-78.

25. Muqattash R, Niankara I, Traoret RI. Survey data for COVID-19 vaccine preference analysis in the United Arab Emirates. Data in Brief. 2020.

26. Trudeau JM, Alicea-Planas J, Vásquez WF. The value of COVID-19 tests in Latin America. Economics and Human Biology. 2020.
27. Echazu L, Nocetti DC. Willingness to pay for morbidity and mortality risk reductions during an epidemic. Theory and preliminary evidence from COVID-19. GENEVA Risk and Insurance Review. 2020. p. 114-33.

28. Ezat $S$, Puteh W. Willingness to Pay for Drugs in Future National Health Financing Scheme among Malaysian Population. 2016; (January 2014).

29. Harapan H, Wagner AL, Yufika A, Winardi W, Anwar S, Gan AK, et al. Willingness-topay for a COVID-19 vaccine and its associated determinants in Indonesia. Hum Vaccines Immunother [Internet]. Taylor \& Francis; 2020;16(12):3074-80. Available from: https://doi.org/10.1080/21645515.2020. 1819741

30. Berghea F, Berghea CE, Abobului M, Vlad VM. Willingness to Pay for a for a Potential Vaccine Against SARS-CoV-2 / COVID-19 Among Adult Persons. 2020;1-11.

31. Azzeri A, Shabaruddin $F$, Jaafar $H$, Mohamed R, Dahlui M. Out-of-Pocket Healthcare Expenditure in Various Household Income Groups Among Patients with Hepatitis C Disease Stages: Findings from. Value in Health Regional Issues [Internet]. 2018 [cited 2021 Apr 17]. p. S147. Available from: https: / / www. valuehealthregionalissues.c om/article/S2212-1099(20)303472 /abstract

32. Gallagher J. Covid vaccine update: when will others be ready? BBC News. 2020.

33. MyMetro. Malaysia tunggu keberkesanan vaksin Covid-19 [Internet]. Harian Metro. 2020 [cited 2021 Feb 1]. Available from: https: / /www.hmetro.com.my/mutakhir/ 2020/12/648660/malaysia-tunggukeberkesanan-vaksin-covid-19-metrotv

34. Lee HY, Lee J, Kim NK. Gender Differences in Health Literacy Among Korean Adults: Do Women Have a Higher Level of Health Literacy Than Men? Am J Mens Health [Internet]. SAGE Publications Inc.; 2015 Sep 13 [cited 2021 Feb 3];9(5):370-9. Available from: http://journals.sagepub.com/doi/10.117 7/1557988314545485 